\title{
Topografia do Brasil profundo: \\ votos, cargos e alinhamentos \\ nos municípios brasileiros
}

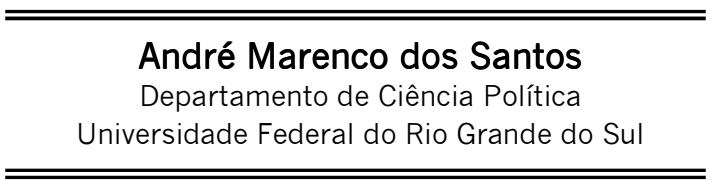

\begin{abstract}
Resumo: 0 propósito deste artigo é identificar os padrões preponderantes da competição política realizada nos municípios brasileiros. Pretende-se analisar dois problemas: em primeiro lugar, considerando-se a estrutura federativa do Estado brasileiro e a presença de governo dividido, busca-se identificar as forças que presidem as relações intergovernamentais entre governo federal, estadual e municipal. Em segundo lugar, procura-se analisar em que medida o incremento na competição eleitoral ao nível nacional tem contribuído para incentivar disputas locais e minar as bases tradicionais de poder nos mais de 5,5 mil municípios brasileiros.
\end{abstract}

Palavras-chave: política municipal; partidos; federalismo; eleições

Abstract: The purpose of this study is to identify the main patterns of political competition in Brazilian municipalities. It intends to analyze two questions: first, considering the federative structure of the Brazilian state and the presence of a divided government, it tries to identify the forces that preside the intergovernmental relations between the federal, state and municipal levels; and second, to what extent the increase in electoral competition at the national level has stimulated the local disputes and undermined the traditional bases of politics in more than 5,500 Brazilian municipalities.

Keywords: local politics; parties; federalism; elections

OPINIÃO PÚBLICA, Campinas, vol. 19, no 1, junho, 2013, p. 1-20 
O propósito deste artigo é identificar os padrões preponderantes da competição política realizada nos municípios brasileiros, respondendo a duas perguntas: em primeiro lugar, considerando-se a estrutura federativa do Estado brasileiro e a presença de governo dividido, busca-se identificar as forças que presidem as relações intergovernamentais entre governo federal, estadual e municipal. Paralelamente, procura-se analisar em que medida o incremento na competição eleitoral ao nível nacional tem contribuído para incentivar disputas locais e minar as bases tradicionais de poder nos mais de 5,5 mil municípios brasileiros. O artigo está dividido em três seções: na primeira, é realizada uma radiografia dos municípios brasileiros, considerando variáveis demográficas, como tamanho, taxas de urbanização, Índice de Desenvolvimento Humano e desigualdade de renda, aferida pelo Índice de Gini. Ainda nesta seção, são examinados fatores relacionados à estrutura de governo, como tamanho, composição e grau de profissionalização do serviço público local, gasto público e a existência de programas e serviços relacionados à administração municipal. Na segunda seção, são descritas as bases de poder e competição política nos municípios. Na terceira, apresenta-se um diagnóstico sobre a competição eleitoral no plano local, considerando o grau de dominância e a força local dos partidos nacionais, além do efeito isolado de alinhamentos estaduais e federais, sobre a competição municipal.

\section{Uma radiografia dos municípios brasileiros}

O Brasil é uma federação que combina centralização de recursos fiscais com descentralização política e administrativa. O Governo Federal é responsável por 52\% da receita pública, restando $29 \%$ para os estados e $18 \%$ para municípios. Seu desenho institucional apresenta os contornos de um modelo de governo dividido, nos planos vertical e horizontal. Na esfera federal, apresenta estrutura convencional de separação de poderes, com Executivo presidencial, eleito por regra majoritária com runoff, Congresso bicameral, incongruente e simétrico, com Senado eleito por maioria simples e Câmara dos Deputados formada por representação proporcional com listas abertas e distritos de magnitude elevada (ANASTASIA, CASTRO \& NUNES, 2008; AMORIM NETO, 2009). Elevada fragmentação partidária e ausência de maioria unipartidária configuram um modelo de "presidencialismo de coalizão" (ABRANCHES, 1988; FIGUEIREDO \& LIMONGI, 1999; SANTOS, 2003). Um Poder Judiciário independente com atributos de revisão de constitucionalidade completa um quadro com a presença de múltiplos veto-players. Nos níveis subnacionais de governo, o país está dividido em 26 estados e um Distrito Federal, que elegem seus respectivos governadores e Assembleias Legislativas. Finalmente, possui 5.563 municípios, dirigidos por um Prefeito, seu secretariado e a Câmara Municipal, formada por representação proporcional (SouZA, 2003; Kerbauy, 2005; Piquet \& AlmeidA, 2008). Extensão territorial e heterogeneidade econômica e social reforçam os elementos de dispersão presentes nas relações intergovernamentais: o PIB per capita do Piauí, o estado mais pobre (U\$4,7 mil), é quase dez vezes menor ao valor encontrado no Distrito Federal (U\$ 40,7 mil) (IBGE, 2009); enquanto o Índice do Desenvolvimento Humano registrado em Santa Catarina $(0,822)$ e Distrito Federal $(0,844)$ corresponde a um patamar alto em qualidade de vida, o valor para o Maranhão $(0,636)$ equipara-se ao observado na Namíbia (PNUD, 2003).

Dos mais de 5,5 mil municípios espalhados por seu território, pouco menos da metade $(45,9 \%)$ podem ser classificados, de acordo com seu tamanho, como micro municípios (com menos de 10 mil 
MARENCO DOS SANTOS, A. Topografia do Brasil profundo: votos, cargos e...

habitantes cada um). Contudo, a população somada destas pequenas cidades representa pouco mais de $7 \%$ do total dos brasileiros. No extremo oposto, há 245 grandes municípios (ou 4,4\% das administrações locais) com mais de 100 mil habitantes, que representam pouco mais da metade da população brasileira. Como seria de se esperar, taxas de urbanização variam conforme a escala dos municípios, alcançando patamar próximo a $80 \%$ nas grandes metrópoles, onde também verificam-se níveis mais elevados de qualidade de vida, medidos pelo Índice de Desenvolvimento Humano. Considerando o Índice de Gini médio para cada tamanho de município, encontramos níveis elevados de concentração na distribuição de renda, independente do tamanho ou taxa de urbanização das cidades. O município com maior desigualdade de renda é Jutaí $(0,82)$, no estado do Amazonas, enquanto a menor concentração de renda encontra-se em Santa Maria (0,36), no Rio Grande do Sul, estado onde se localizam 8 dos 10 municípios com menor Índice de Gini.

Diferenças significativas entre os municípios associadas a seu tamanho podem ser percebidas quando examina-se a estrutura do serviço público e a provisão de políticas urbanas que constituem responsabilidade do governo municipal. A dimensão do serviço público na administração municipal, medido pelo percentual de funcionários públicos municipais em relação à população de cada cidade, apresenta variação decrescente à medida em que saímos dos menores municípios em direção aos maiores. Nos municípios com população inferior a 10 mil habitantes, os funcionários públicos representam $5,3 \%$ dos habitantes, caindo para menos da metade desta proporção nos maiores centros urbanos.

Além de medir o tamanho relativo do serviço público, parece relevante um esforço na direção de examinar sua composição, considerando em especial a presença de um perfil mais profissionalizado, com funcionários de carreira recrutados por concurso público ou, em oposição, a permanência de formas de recrutamento para postos públicos baseados em patronagem política ou spoil system, quando o preenchimento de cargos está baseado na possibilidade de indicação pelo governante, geralmente em troca de apoios, votos ou lealdade política e/ou pessoal (BoISSEVAIN, 1966; SCOTT, 1977; LANDÉ, 1977; GraZIANO, 1977). Estudo do Banco Interamericano de Desenvolvimento (2007), focado em 18 países da América Latina, considerou a presença de quatro tipos de burocracias públicas nas instituições públicas da região, em função: a) do grau de autonomia que dispõe frente a governos e b) de sua capacidade técnica - burocracias meritocráticas (alta autonomia e capacidade), administrativas (alta autonomia, baixa capacidade), clientelista (baixa autonomia e capacidade) e paralelas (baixa autonomia e alta capacidade). Deixando de lado os tipos de burocracia administrativa e paralela, e fixando-se como parâmetros nos extremos configurados pelos modelos meritocrático e clientelístico, pode-se identificar, através da Tabela 1 , sua presença diferenciada no conjunto de municípios. Cargos de confiança (CCs) oferecem uma proxy adequada para um recorte do fenômeno do spoil system. Embora a Constituição Federal de 1988 tenha determinado a realização de concurso público como procedimento de seleção de cargos administrativos abaixo dos postos de primeiro escalão (ministros, secretários), ainda há quantidade significativa de cargos públicos nos níveis federal, estadual e municipal cujo provimento pode ser feito por livre nomeação pelo titular do Poder Executivo, e que são frequentemente utilizados como 
OPINIÃO PÚBLICA, Campinas, vol. 19, nº 1, junho, 2013, p. 1-20

moeda para o pagamento de apoio e lealdade política passada ou futura. Esta forma de nomeação é mais frequente nos municípios menores, com ligeiro declínio à medida em que se chega a cidades de porte médio. Em Maraial, por exemplo, pequeno município com 12,4 mil habitantes e IDH baixo $(0,560)$ no estado de Pernambuco, 72,3\% dos funcionários públicos são ocupantes de cargos de confiança.

Tabela 1

Radiografia dos Municípios Brasileiros

\begin{tabular}{|c|c|c|c|c|c|}
\hline & & $\begin{array}{c}\text { MICRO } \\
\text { (menos de } 10 \\
\text { mil habitantes) }\end{array}$ & $\begin{array}{c}\text { PEQUENO } \\
\text { (de } 10 \text { a } 20 \\
\text { mil hab.) }\end{array}$ & $\begin{array}{c}\text { MÉDIO } \\
\text { (de } 20 \text { a } 100 \text { mil } \\
\text { hab.) }\end{array}$ & $\begin{array}{c}\text { GRANDE } \\
\text { (mais de } 100 \text { mil } \\
\text { habitantes) }\end{array}$ \\
\hline \multirow{5}{*}{$\begin{array}{l}D \\
E \\
M \\
O \\
G \\
R \\
A \\
F \\
I \\
A\end{array}$} & Municípios (em \%) & 45,9 & 24,9 & 24,4 & 4,4 \\
\hline & População (em \%) & 7,1 & 10,5 & 28,5 & 53,9 \\
\hline & IDH & 0.66 & 0.64 & 0.66 & 0.75 \\
\hline & Gini & 0.55 & 0.57 & 0.58 & 0.56 \\
\hline & $\%$ população urbana & 53,7 & 51,9 & 61,4 & 79,4 \\
\hline \multirow{10}{*}{$\begin{array}{l}\mathrm{G} \\
0 \\
\mathrm{~V} \\
\mathrm{E} \\
\mathrm{R} \\
\mathrm{N} \\
\mathrm{O}\end{array}$} & $\begin{array}{l}\text { Funcionários públicos, \% em relação } \\
\text { população }\end{array}$ & 5,3 & 3,9 & 3,4 & 2,2 \\
\hline & $\begin{array}{l}\text { Cargos de confiança, \% em relação } \\
\text { funcionários públicos }\end{array}$ & 11,5 & 9,4 & 8,6 & 9,1 \\
\hline & $\begin{array}{l}\text { Municípios com mais } 10 \% \text { Cargos de } \\
\text { Confiança em relação funcionários }\end{array}$ & 47,2 & 28,1 & 29,0 & 28,3 \\
\hline & Estatutários com Ensino Superior & 12,9 & 12,3 & 13,9 & 19,7 \\
\hline & Gasto Público per capita (em U\$) & 300 & 200 & 193,20 & 219,40 \\
\hline & $\begin{array}{l}\text { Municípios c/ Plano Municípios c/ } \\
\text { Diretor }\end{array}$ & 11,8 & 19,7 & 77,1 & 97,0 \\
\hline & Municípios c/ Lei Solo & 27,4 & 33,1 & 57,7 & 88,0 \\
\hline & Municípios c/ CMPU & 9,3 & 13,6 & 34,0 & 67,3 \\
\hline & Municípios c/ Código Obras & 39,1 & 51,6 & 72,3 & 90,2 \\
\hline & $\begin{array}{l}\text { Municípios c/ Licenciamento } \\
\text { Ambiental }\end{array}$ & 19,7 & 21,9 & 36,1 & 53,0 \\
\hline
\end{tabular}

Fonte: Instituto Brasileiro de Geografia e Estatística (2009).

No extremo oposto, uma proxy para burocracias meritocráticas pode ser isolada na parcela do funcionalismo municipal composta por estatutários com formação no ensino superior. Estatutários são os funcionários de carreira, ingressados através de concurso público, com estabilidade no emprego após 2 ou 3 anos de serviço ${ }^{1}$, o que Ihes confere proteção em relação à demissão no cargo por discricionariedade política. Diploma superior e concurso público conferem os requisitos de capacidade técnica. O município de Campos, no Rio de Janeiro, com 432 mil habitantes (84\% em zona urbana) apresenta $63 \%$ de seus servidores públicos constituídos por estatutários com diploma superior.

\footnotetext{
${ }^{1}$ Após 2003, o período de estágio probatório foi ampliado para três anos.
} 
MARENCO DOS SANTOS, A. Topografia do Brasil profundo: votos, cargos e...

Em contraste com maior escala da administração e no gasto público per capita, a provisão de serviços e programas de responsabilidade municipal é significativamente menos frequente à medida em que passamos dos grandes para os menores municípios. O Plano Diretor representa a principal diretriz de planejamento de cada município, fixando normas para a ocupação do espaço físico, determinando o que pode ou não ser construído, e estabelecendo a oferta de serviços públicos. A Constituição Federal de 1988 (art. 182, $\S 1^{\circ}$ ) tornou obrigatória a sua elaboração e aprovação pelas respectivas Câmaras Municipais, em todos os municípios. Entretanto, passados 22 anos, esta decisão não foi implementada por 8 em cada 10 micro e pequenos municípios. Leis para o uso do solo urbano deveriam fixar parâmetros para o parcelamento ou desmembramento do espaço físico municipal; Códigos de Obras são legislações municipais que dispõem sobre as regras gerais e específicas a serem obedecidas no projeto, licenciamento, execução, manutenção e utilização de obras e edificações, dentro dos limites dos imóveis; o licenciamento ambiental corresponde ao conjunto de obrigações legais prévia à instalação de qualquer empreendimento ou atividade potencialmente poluidora ou degradadora do meio ambiente; finalmente, Conselhos Municipais de Política Urbana são órgãos gestores das políticas de uso do solo nos municípios, formados por representantes do governo municipal, poder legislativo, administrações estadual e federal, organizações associativas e não governamentais e outras instituições públicas como universidades e fundações. Tanto a legislação específica que regula a ocupação do espaço físico e seu impacto ambiental como a presença de um órgão colegiado com atribuições de propor e monitorar medidas para o uso de solo e equipamentos urbanos constituem elementos de política pública em escala municipal. A presença de um dos dois ou de ambos varia conforme o tamanho do município, de quase ausentes na grande maioria das micro e pequenas localidades à alta frequência nas médias e grandes cidades.

\section{Bases do poder e competição nos municípios brasileiros}

Desta configuração das cidades brasileiras, resultam dois tipos de interrogações: 1) Que padrão predomina nas relações intergovernamentais entre autoridades federais, estaduais e municipais? Dispersão, na qual governos locais preservam sua autonomia e são capazes de fazer valer suas preferências sobre os níveis federal e estadual, ou concentração, quando a fragilidade e dependência financeira dos municípios faz com que prevaleça a capacidade do governo federal para submeter autoridades locais? 2) Em que medida o incremento da competição eleitoral nos níveis federal e estadual afeta a política nos municípios, contribuindo para enfraquecer as bases tradicionais de poder existentes na esfera local? Dahl (1971) chama a atenção para a possibilidade de haver instituições configuradas por alto grau de competição nos níveis nacionais, em contraste com a permanência de bases tradicionais de poder concentrado nos níveis subnacionais. Até que ponto este prognóstico é válido para descrever a dinâmica da política brasileira nos níveis locais de governo?

Nos últimos anos, avançou-se muito na compreensão de como se governa o Brasil no plano federal: relações entre Executivo e Congresso nacionais (FIGUEIREDO \& LIMONGI, 1999; PALERMO, 2000; Amorim Neto, 2000; Ames, 2003; PEREIRA, POWER \& RENNÓ, 2008), estrutura interna e processos decisórios na arena legislativa (INÁCIO \& RenNó, 2009), dinâmica do Poder Judiciário (ViannA, Melo, CaRVALho e 
BURGOS, 1997; SADEK, 2006), comportamento eleitoral em eleições majoritárias e proporcionais (Carvalho, 2003; Nicolau \& Power, 2007; Almeida, 2008; Lavareda, 2009). A despeito disto, a compreensão acerca da política nos mais de 5 mil municípios brasileiros apresenta-se como uma caixa. preta e boa parte das controvérsias acerca de sua dinâmica ainda é caudatária de interpretações formuladas na primeira metade do século XX sobre política local e suas conexões com governos estaduais e federal (CARVALHO, 1997). Pode-se encontrar inúmeros e densos estudos de caso sobre municípios e as relações de poder em escala local (CARVAlHo, 1966; LoPEZ, 2004). A carência, contudo, diz respeito à ausência de interpretações capazes de identificar padrões de autoridade política municipal, bem como da natureza dos vínculos entre governos municipal, estadual e federal.

Uma primeira destas matrizes analíticas identificou no poder municipal o fenômeno do mandonismo, traduzido na presença de potentados oligárquicos locais, relativamente isolados face aos níveis superiores de governo, cuja fonte de poder remontava a bases tradicionais de domínio sobre populações rurais, fundadas na propriedade da terra (QUeIROZ, 1976; PANG, 1979). Como lembra Carvalho (1997), este fenômeno é correlato ao caciquismo encontrado em vários países da América espanhola.

Outra interpretação foi formulada a partir do trabalho clássico de Victor Nunes Leal, Coronelismo, enxada e voto (1975). Para Leal, o coronelismo constitui um fenômeno temporalmente datado, circunscrito à chamada República Velha (1889-1930), e gerado pela combinação do poder adquirido pelos governadores de estado, com a decadência econômica dos proprietários de terras. A fórmula política - conhecida como política dos Estados ou política dos governadores - que caracteriza as instituições políticas brasileiras do período fora plasmada na presidência de Campos Sales (1898-1902), quando a ausência de um partido nacional capaz de dotar-Ihe da maioria congressual necessária para aprovar projetos de saneamento econômico e fiscal, o conduz a formular um pacto com os governadores estaduais, naquele momento reforçados pelo federalismo fiscal e controle sobre efetivos militares estaduais: em troca do apoio político, o Presidente conferiu margens de autonomia para que estes governadores exercessem poder político em seus estados, sem interferência externa. Por sua vez, governadores formularam pacto semelhante com coronéis e chefes políticos municipais. Em troca da lealdade destes, o governo estadual concede-Ihes a prerrogativa de exercer domínio sobre a população local, acesso a verbas e nomear cargos públicos no município (juiz, delegado de polícia, coletor de impostos, professora primária), convertidos em fonte de poder para estes. Em direção convergente, Hagopian (1986) chama a atenção para as mudanças provocadas pela centralização estatal sobre o clientelismo tradicional fundado na propriedade da terra, em direção a um padrão de trocas clientelísticas no qual o controle sobre recursos públicos (cargos e verbas) constitui a moeda política mais forte.

Uma interrogação necessária diz respeito a quanto ainda podemos basear-nos nestes modelos analíticos para explicar a política local e o padrão de relação intergovernamentais entre municípios, estados e o governo federal? Pode-se identificar um conjunto de fatores que mudaram a topografia da estrutura política municipal e de suas relações com autoridades estaduais e federais. Em primeiro lugar, 
MARENCO DOS SANTOS, A. Topografia do Brasil profundo: votos, cargos e...

deve-se considerar o impacto do processo de urbanização verificado especialmente a partir dos anos 1960: em 1950, a população rural representava cerca de $64 \%$ dos brasileiros, caindo para $44 \%$ em 1970, tornando-se apenas $20 \%$ no último censo populacional, realizado no ano 2000 (IBGE, 2000). 0 êxodo da população rural para as cidades terminou por corroer a reserva de votos tradicionais, moeda com a qual chefes políticos municipais podiam negociar em troca de patronagem e verbas públicas.

Qual o efeito presumível do processo de urbanização sobre a competição eleitoral nos municípios brasileiros? Conforme Campello de Souza (2006), sua influência é percebida sob a forma da constituição de dois subsistemas partidários: competitivo nos maiores municípios e centros urbanos e oligárquico ou não-competitivo nos pequenos municípios, marcados pela presença ainda expressiva de população rural. Da mesma forma, Kerbauy, em artigo voltado para o exame do Poder Legislativo em escala local, verifica a presença de uma tensão entre uma lógica clientelista e outra fundada em procedimentos universais (KERBAUY, 2005). Na mesma direção, Avelar e Walter (2008), analisando as eleições municipais de 1996, 2000 e 2004, registraram os efeitos da mudança socioeconômica provocada pela urbanização sobre a manutenção de bases da política tradicional. Seus achados mostraram a predominância de partidos de centro e esquerda em cidades com alto Índice de Desenvolvimento Humano (IDH), de partidos de centro em cidades com IDH médio e partidos conservadores tradicionais em municípios pequenos e com pior qualidade de vida. É neste contexto tradicional que é possível identificar maior frequência de continuidade do mesmo partido a frente do governo municipal. Em resumo, em municípios com menor urbanização e/ou industrialização, mudanças políticas e incremento na competição eleitoral ocorreriam de modo mais lento.

Em direção oposta a este argumento, Piquet \& Almeida (2008) concluíram não haver diferenças significativas nos padrões de competição eleitoral e força partidária baseadas no tamanho de cada município. Conforme estes autores, o sistema partidário local não possui uma dinâmica inteiramente autárquica, prevalecendo, ao contrário, sua articulação aos subsistemas partidários estaduais e nacional.

Paralelamente a estes fatores demográficos, há que considerar as consequências provocadas pelos arranjos institucionais que definem as relações intergovernamentais sobre o grau de competição na política local. Um primeiro fator diz respeito à moldura estabelecida pelo calendário eleitoral. Enquanto a eleição de presidentes, governadores e prefeitos de capitais e cidades classificadas como áreas de segurança foi interrompida por duas décadas de regime autoritário (1964-1985), com a indicação de seus titulares transferida para colégios eleitorais indiretos sob o controle dos militares, as eleições para governos municipais na grande maioria das cidades pequenas e médias não sofreram interrupção, mesmo durante esse período. Eleições para governadores estaduais voltaram a ser disputadas apenas em 1982, já no final do regime autoritário, e eleições presidenciais diretas, somente em 1989, quatro anos após a redemocratização do país. Desta forma, ocorreram três eleições para autoridades municipais (1968, 1972 e 1976) dentro do governo militar e antes do retorno das eleições para autoridades estaduais. O efeito esperado desta sequência (local > estadual > nacional) pode ser verificado no reforço de vínculos de lealdade locais, constituídos nas disputas em torno ao único posto executivo não interditado pelos militares. Por outro lado, após a redemocratização, o calendário de 
eleições no país apresenta dois ciclos distintos: eleições municipais para prefeitos e legisladores são realizadas em anos distintos à escolha de representantes federais e estaduais (Presidente, Senadores, Deputados Federais, Governadores de Estado, Deputados Estaduais), o que deveria reforçar uma dinâmica localista para a competição municipal. Finalmente, a Constituição brasileira aprovada em 1988 promoveu uma descentralização na gestão de serviços públicos, com ampliação da receita fiscal controlada pelos municípios (ALMEIDA \& CARNEIRO, 2003; TOMIO, 2005).

Outros fatores institucionais estão relacionados à formação de coalizões de governo. Em decorrência da elevada fragmentação partidária no Congresso brasileiro, Presidentes da República são obrigados a montar grandes coalizões como preço para assegurar maioria legislativa. A implicação disto para os níveis subnacionais de governo se dá sob a forma de uma multiplicação de canais partidários de acesso a recursos governamentais e transferências de verbas federais. Como consequência, deve-se encontrar maior longevidade de forças políticas tradicionais nos municípios, com processos de mudança política e incremento na competição eleitoral local em ritmo mais lento do que o verificado ao nível federal. A consolidação do presidencialismo de coalizão, como estrutura institucional a moldar as relações entre Executivo e Legislativo no plano federal, termina por comprometer o monopólio de acesso a cargos e verbas federais controlados por um único cacique local, criando condições mais propícias à competição local entre diferentes candidatos ou partidos com acesso aos governos estaduais e federal.

Trata-se de analisar, assim, em que medida fatores como urbanização e heterogeneidade de grandes coalizões contribuem para tornar mais competitiva a disputa política travada nos municípios brasileiros.

\section{Alinhamentos políticos nos municípios}

O objetivo desta seção consiste em analisar o incremento da competição eleitoral local, a escala das mudanças políticas verificadas nos governos municipais e a medida em que este processo tem produzido um enfraquecimento nas bases locais da política tradicional no Brasil. Duas variáveis são consideradas para avaliar o padrão de competição eleitoral nos municípios: o nível de dominância eleitoral e a distribuição de Prefeituras Municipais entre os partidos nacionais.

Por dominância eleitoral compreende-se aqui o grau de concentração eleitoral existente em cada município, medido pelo percentual de votos obtido pelo partido vencedor em cada eleição para o governo municipal. Seguindo as indicações oferecidas pela escala de competição eleitoral elaborada por Vanhanen (2000), adota-se a premissa de que a proporção de votos do candidato vencedor oferece um indicador para aferir o grau de competição e a capacidade de um partido em estabelecer lealdades mais amplas, e neutralizar competidores rivais, reduzindo o espaço de oposição². Em outras palavras, faz diferença um Prefeito municipal ter sido eleito com menos de $50 \%$ dos votos válidos - indicando a presença de oposição forte e competição eleitoral significativa - ou, em situação oposta, um governo municipal com o apoio superior a $60 \%$ dos votos, revelando frágil oposição e reduzida competição

\footnotetext{
${ }^{2}$ A Constituição brasileira de 1988 estabelece que em municípios com mais de 200 mil eleitores, caso nenhum candidato alcance mais de $50 \%$ dos votos válidos, deve ocorrer um segundo turno, entre os dois candidatos com mais votos. Os dados a seguir consideram apenas os resultados de primeiro turno.
} 
MARENCO DOS SANTOS, A. Topografia do Brasil profundo: votos, cargos e...

eleitoral. Nas eleições municipais de 2008, em 248 municípios, o partido vencedor registrou $100 \%$ dos votos válidos, o que se explica pela ausência de outro competidor e a situação de candidato único.

A Tabela 2 oferece um panorama da dominância eleitoral nas eleições municipais brasileiras de 2000, 2004 e 2008 no Brasil, considerando os valores médios segundo o tamanho de cada município:

Tabela 2

Dominância Eleitoral nos Municípios Brasileiros (2000 a 2008) (média de votos segundo tamanho município e eleições diferentes)

\begin{tabular}{|l|c|c|c|c|c|c|c|c|c|c|c|c|}
\hline & \multicolumn{3}{|c|}{ MICRO } & \multicolumn{3}{c|}{ PEQUENOS } & \multicolumn{3}{c|}{ MÉDIOS } & \multicolumn{3}{c|}{ GRANDES } \\
\hline $\begin{array}{l}\% \text { votos } \\
\text { vencedor }\end{array}$ & 2000 & 2004 & 2008 & 2000 & 2004 & 2008 & 2000 & 2004 & 2008 & 2000 & 2004 & 2008 \\
\hline$<50 \%$ & 16,7 & 19,5 & 14,1 & 21,7 & 27,2 & 20,7 & 32,5 & 39,6 & 30,8 & 46,6 & 60,9 & 34,9 \\
\hline 50 a $60 \%$ & 53,4 & 57,1 & 58,1 & 55,1 & 54,8 & 56,5 & 45,9 & 45,5 & 44,8 & 28,0 & 24,8 & 38,3 \\
\hline$>60 \%$ & 29,9 & 23,4 & 27,8 & 23,2 & 18,0 & 22,8 & 21,5 & 14,9 & 24,5 & 25,4 & 14,3 & 26,8 \\
\hline
\end{tabular}

Votações abaixo de 50\% correspondem a um comportamento esperado: são pouco frequentes em micro e pequenos municípios, onde a escala demográfica, concentração de oportunidades econômicas ou acesso restrito à informação dificultam a constituição de uma arena eleitoral pluralista e competitiva, alcançando frequências mais significativas (em torno a $1 / 3$ dos casos) nos grandes municípios. Por outro lado, as correlações encontradas para a associação entre população urbana e percentual de votos do partido vencedor não foram significativas em nenhum dos anos analisados: 0,013 (2000), -0,026(2004) e -0,021 (2008). Neste caso, a escala - e não a estrutura econômica - parece ser o fator preponderante. Enquanto em pequenos municípios (rurais ou urbanos) vínculos pessoais ainda predominam, reduzindo espaço para competição, nos grandes centros urbanos a escala populacional e a impessoalização das relações públicas e de mercado favorecem a constituição de uma arena eleitoral competitiva. Mais complexo e inesperado parece ser o registro de votações acima de $60 \%$ dos votos, o que indica uma condição de domínio eleitoral seguro, distribuídas de forma independente em relação ao tamanho dos municípios. Ou seja, a probabilidade de encontrar-se, sobretudo nas eleições de 2000 e 2008, governos municipais com patamar de votos próximo ou superior a $2 / 3$ - e uma correspondente fragilidade de oposições - é indiferente mesmo quando muda-se a observação, de micro e pequenos municípios, em direção aos grandes centros urbanos.

Enquanto nos micro e pequenos municípios a explicação pode estar - como apontado anteriormente - na escala demográfica que reforça vínculos de lealdade pessoais, a presença em proporção equivalente, de autoridades eleitas com mais de $60 \%$ dos votos em grandes municípios, pode representar um desafio à compreensão do fenômeno. Para explicá-lo, deve-se recordar mudanças nas regras de eleição dos governos executivos, introduzidas pela Constituição de 1988. Desde 1990, a eleição de Presidentes da República, Governadores de Estado e Prefeitos de municípios com mais de 200 mil eleitores (municípios grandes, portanto) ocorre por majority runoff, com a realização de uma 
segunda volta eleitoral quando nenhum dos competidores alcança $50 \%$ mais um dos votos válidos. Ao contrário de incrementar a fragmentação na oferta de candidatos - fenômeno apontado na literatura (DUVERGER, 1951; CoX, 1997) - isto tem provocado uma antecipação na coordenação eleitoral (CoX, 1997), com a promoção de grandes coalizões já na primeira volta eleitoral. Em seguida, nova mudança na legislação eleitoral, com a permissão de reeleição imediata para incumbents, reforçou o potencial destes para manter-se no posto, multiplicando a capacidade de coordenação de grandes coalizões eleitorais (CARDERELLO, 2009). Para diminuir a incerteza provocada por uma segunda volta eleitoral, incumbents promovem coalizões sobredimensionadas, fenômeno que se apresenta sob a forma de elevados percentuais de votos obtidos por candidatos vencedores, mesmo em grandes municípios.

Indo além da dominância eleitoral, e examinando o perfil ideológico dos partidos vencedores no governo executivo dos municípios brasileiros, temos oportunidade para reencontrar a velha hipótese, derivada da teoria da modernização, que procura associar desenvolvimentos econômico e social com desenvolvimento político (LIPSET, 1959; EISENSTADT, 1966; DEUTSCH, 1970; SHILS, 1974). A suposição que orienta esta tese procura destacar a relação entre as mudanças provocadas na estrutura econômica a partir do incremento da industrialização e comércio, seus impactos demográficos medidos pelas taxas de urbanização, queda no analfabetismo e aumento na escolaridade da população. Seus efeitos sobre o comportamento político deveriam ser sentidos sob a forma da redução na reserva de votos e apoios políticos dos partidos tradicionais de base rural, e na formação de um eleitorado urbano independente e com níveis elevados de informação política, traduzido em reforço no associativismo e no apoio a partidos reformistas. No Brasil, esta tese expressou-se através de uma importante linha de interpretação sobre as mudanças verificadas na competição eleitoral e partidária a partir do final dos anos 1950, com ênfase posta no declínio da política tradicional e clientelista e sua substituição por política ideológica, como resultado do desenvolvimento e modernização (CAMPELLO DE SOUZA, 1976; JAGUARIBE, 1962; SOARES, 1973).

Para verificar se as mudanças observadas na política municipal poderiam estar associadas aos efeitos de sua modernização social, empregou-se como proxy deste desenvolvimento econômico a variável urbanização, considerando o percentual de população urbana em cada município. Uma primeira aproximação ao sistema partidário local foi promovida agregando-se os partidos segundo sua família ideológica, conforme classificação convencional, empregada em outros estudos (FIGUEIREDO \& LIMONGI, 1999; RODRIGUES, 2002; 2006). Se a hipótese da modernização oferecer a chave para a compreensão sobre a competição eleitoral nos municípios brasileiros, devemos encontrar uma relação entre maior força de partidos conservadores tradicionais (direita) e cidades menos urbanizadas, com crescimento e força de partidos reformistas de centro e esquerda à medida em que aumenta a proporção de população urbana. 
MARENCO DOS SANTOS, A. Topografia do Brasil profundo: votos, cargos e...

Tabela 3

Prefeituras por famílias ideológicas, conforme \% urbanização

\begin{tabular}{|c|c|c|c|c|}
\hline \multirow{2}{*}{} & \multicolumn{4}{|c|}{ Urbanização (\%) } \\
\cline { 2 - 5 } & Até 40 & 40 a 60 & 60 a 80 & Mais de 80 \\
\hline Direita & 39,0 & 39,0 & 37,6 & 31,6 \\
\hline Centro & 34,1 & 36,1 & 36,8 & 38,1 \\
\hline Esquerda & 26,9 & 24,9 & 25,6 & 30,4 \\
\hline
\end{tabular}

Fonte: Tribunal Superior Eleitoral (TSE); Instituto Brasileiro de Geografia e Estatística (IBGE).

Isto, entretanto, não ocorre, ou ao menos não se verifica em escala significativa. Partidos conservadores controlam - como se poderia esperar - 39\% dos municípios com população predominante rural (Tabela 3). Nestes casos ainda localizam-se as diferenças mais pronunciadas entre a força de partidos de direita e esquerda. Contudo, quando nos movemos em direção a cidades com forte urbanização (mais de $80 \%$ de sua população morando em zona urbana), ainda assim, encontramos $31,6 \%$ dos governos municipais controlados por partidos de direita. Em paralelo, a diferença na implantação política dos partidos de esquerda, entre municípios rurais $(26,9 \%)$ e fortemente urbanos $(30,4 \%)$ é de apenas 3,5 pontos percentuais, indicando que a configuração demográfica não constitui uma variável relevante para explicar os resultados da competição eleitoral.

A análise até aqui baseou-se em uma agregação dos partidos segundo suas respectivas famílias ideológicas. A leitura de diferentes estudos sobre o sistema partidário brasileiro deve ser útil para advertir quanto aos riscos contidos neste tratamento analítico, ao desprezarem-se diferenças interpartidárias, significativas dentro de cada bloco ideológico (RodRIGUES, 2006; BRAGA, 2006). O sistema partidário brasileiro apresenta alta fragmentação, com mais de 20 legendas representadas no Congresso Nacional, gerando um número efetivo de partidos, mensurado pelo índice Laakso-Taagepera, que oscila entre 8 e 9.

Para examinar a presença dos principais partidos nacionais na política local, na sequência, são consideradas apenas legendas partidárias que obtiveram mais de 5\% das cadeiras nas últimas 5 eleições para a Câmara dos Deputados. Isto resultou na identificação dos sete principais partidos brasileiros na esfera federal: PFL/DEM, PP, PSDB, PMDB, PDT, PT, PSB. A Tabela 4 considera a força política destes partidos nos municípios brasileiros, medida pelo percentual de prefeituras conquistadas por cada partido. Esta informação foi ainda desagregada, considerando-se o tamanho dos municípios e sua expressão nas eleições municipais de 2000, 2004 e 2008. 
OPINIÃO PÚBLICA, Campinas, vol. 19, no 1, junho, 2013, p. 1-20

Tabela 4

Força partidária conforme \% Prefeituras (segundo tamanho do município e ano de eleição)

\begin{tabular}{|c|c|c|c|c|c|c|c|c|c|c|c|c|}
\hline & \multicolumn{3}{|c|}{ MICRO } & \multicolumn{3}{|c|}{ PEQUENOS } & \multicolumn{3}{|c|}{ MÉDIOS } & \multicolumn{3}{|c|}{ GRANDES } \\
\hline & 2000 & 2004 & 2008 & 2000 & 2004 & 2008 & 2000 & 2004 & 2008 & 2000 & 2004 & 2008 \\
\hline PFL/DEM & 19,2 & 14,6 & 10,1 & 21,0 & 15,9 & 8,1 & 15,3 & 12,1 & 7,6 & 12,4 & 10,9 & 7,9 \\
\hline PP & 13,6 & 11,4 & 11,5 & 8,4 & 9,2 & 9,1 & 10,4 & 9,0 & 8,4 & 3,8 & 3,0 & 5,3 \\
\hline PMDB & 25,3 & 20,8 & 22,5 & 20,9 & 18,1 & 22,3 & 20,6 & 17,5 & 19,1 & 12,8 & 13,9 & 18,8 \\
\hline PSDB & 17,1 & 15,1 & 13,9 & 17,6 & 15,2 & 13,7 & 18,8 & 16,4 & 15,0 & 17,3 & 18,0 & 15,8 \\
\hline PDT & 4,7 & 5,8 & 5,8 & 4,5 & 4,7 & 6,4 & 6,0 & 5,4 & 6,7 & 7,9 & 7,5 & 7,5 \\
\hline PSB & 1,5 & 2,7 & 5,1 & 2,3 & 3,4 & 6,1 & 3,5 & 2,9 & 5,8 & 4,5 & 6,0 & 4,9 \\
\hline PT & 2,1 & 6,1 & 8,6 & 2,9 & 7,4 & 8,4 & 3,4 & 7,9 & 11,8 & 12,8 & 16,9 & 21,8 \\
\hline
\end{tabular}

Fonte: Tribunal Superior Eleitoral (TSE); Instituto Brasileiro de Geografia e Estatística (IBGE).

O dado que mais chama a atenção é o declínio linear da força política do PFL/DEM, qualquer que seja o tamanho do município. O principal partido conservador brasileiro perdeu cerca de metade de suas prefeituras, mesmo em municípios micro, pequenos e médios. No extremo oposto, o PT quadruplicou sua força nas micro e pequenas cidades, triplicou nas médias e incrementou em $70 \%$ sua presença em prefeituras de grandes municípios. Este crescimento pode também ser verificado nos desempenhos do PDT e do PSB nos municípios micro, pequenos e médios. Contudo, seria leitura apressada concluir que a explicação para estes resultados discrepantes residiria exclusivamente na tendência ideológica, declínio da direita e crescimento da esquerda. Um exame mais detalhado, considerando cada eleição, permite constatar que enquanto o PFL/DEM entra em queda livre, seu par direitista PP mantém-se estável; enquanto o PSDB acompanha o declínio de seu parceiro oposicionista, o outro partido de centro - PMDB - reverte tendência de queda, melhorando seu desempenho em todos os tamanhos de município na eleição de 2008. Que fortuna explicaria a tendência de perda de força política do direitista PFL/DEM e do centrista PSDB? O que haveria em comum entre a esquerda (PT, PSB, PDT), e o centrista PMDB de 2008? Se a ideologia não é o fator a explicar crescimento/declínio, qual, então, seria a chave para este fenômeno? Não poderia estar no fato de PFL/DEM e PSDB constituírem as duas principais forças de oposição ao governo federal, entre 2003 e 2010? A despeito de suas diferenças ideológicas, o fato de PT, PSB, PDT, PMDB e PP formarem a coalizão de governo no plano federal (os dois últimos após 2007) poderia estar relacionado à expansão de sua presença nos governos municipais?

À luz dos resultados apresentados na Tabela 4, pode restar dúvida acerca de qual fator parece impactar de forma mais robusta os resultados eleitorais para governos municipais: tendências ideológicas ou alinhamento ao governo federal. Para testar a força de IDEOLOGIA e GOVERNO, procedeu. se a uma regressão logística, buscando mensurar a probabilidade de partidos à frente de governos municipais de 2004, serem reeleitos nas eleições municipais de 2008. Para a classificação ideológica, foi repetido o procedimento adotado anteriormente. Quanto ao critério para alinhamento com o governo federal, consideraram-se os partidos com participação em Ministérios do Governo Federal, classificando. se os partidos à frente de cada uma das 5.563 prefeituras do país em "governo" ou "oposição", conforme seu partido integre ou não a coalizão do governo federal, no momento das eleições municipais. Como variável dependente, foi utilizada dummy de 1 para reeleição e 0 para derrota; as duas variáveis independentes consideradas foram as dummies PARTYGOV (1 para partido integrante da coalizão do 
MARENCO DOS SANTOS, A. Topografia do Brasil profundo: votos, cargos e...

governo federal e 0 para oposição) e LEFT (partido de esquerda $=1$, demais $=0$ ). Foram ainda empregadas outras duas variáveis: REGIAO, isolando nordeste $(=1)$ e as demais $(0)$ e gasto público per capita (GASTO). Os resultados podem ser observados na Tabela 5:

Tabela 5

Regressão Logística: probabilidade de continuidade partidária em função de diferentes variáveis

\begin{tabular}{|c|c|c|c|}
\hline & B & Sig & Odds ratio \\
\hline PARTYGOV & 0.5370 & 0.000 & 1.7109 \\
\hline LEFT & 0.1204 & 0.1299 & 0.8866 \\
\hline REGIAO & 0.1891 & 0.0124 & 0.8277 \\
\hline GASTO & 0.0003 & 0.0630 & 1.0003 \\
\hline Constant & -0.9142 & 0.000 & \\
\hline
\end{tabular}

Fonte: Tribunal Superior Eleitoral (TSE); Instituto Brasileiro de Geografia e Estatística (IBGE).

Quanto a ideologia e quanto integrar o governo federal podem explicar força partidária nas eleições municipais? Analisando os resultados, verifica-se que apenas o alinhamento com o governo federal (PARTYGOV) mostrou-se significativo estatisticamente, fazendo com que partidos governistas no plano federal apresentem cerca de $71 \%$ a mais de chance de vencer nos municípios em relação a partidos de oposição federal. Paralelamente, quando cotejada com a variável governo, ideologia partidária não revelou ser significativa para aumentar as chances eleitorais nos municípios, e os partidos de esquerda apresentaram aproximadamente razão $11 \%$ inferior de conquistar municípios em relação a partidos de centro e direita. Contrariando o bom senso convencional, a força do continuísmo não se verifica de modo mais intenso no eleitorado pobre da região nordeste do Brasil, onde um partido apresenta chance de reeleição cerca de $17 \%$ inferior ao verificado nas demais regiões do país. Tampouco o gasto público per capita parece afetar chances de reeleição partidária. Como isto pode ser interpretado? Partidos de esquerda são mais competitivos quando compartilham postos no governo federal. Partidos de centro e direita mantêm-se competitivos - a despeito das tendências demográficas que Ihes provocam danos - quando participam de cargos executivos federais; partidos de esquerda na oposição ou, de modo mais saliente, legendas de centro e direita fora do governo apresentam os prospectos mais negativos para a conquista ou manutenção de governos locais. De modo não linear, o que os dados sugerem parece ser a ocorrência de um processo de nacionalização das estruturas políticas locais, com a perda de relevância de fatores derivados de poder ou influência locais, e incremento de variáveis associadas a políticas federais, em especial na região nordeste, explicando, desta forma, as menores probabilidades de reeleição ali encontradas. Isto não corresponde, necessariamente, à mudança nos padrões de comportamento do eleitorado, mas, simplesmente, o efeito do controle exercido sobre cargos, verbas e patronagem federal sobre os alinhamentos partidários municipais. Neste caso, as palavras de Leal parecem válidas ainda hoje, sugerindo que facções municipais "batem-se para disputar, entre si, o privilégio de apoiar o governo e nele se amparar" (LEAL, 1975 , p. 49). Isto significaria que alinhamento ao governo federal pode ser relevante para a competição local não como decorrência de um tipo de coattail effect, mas pelo fato de os políticos e lideranças mais importantes no plano municipal adotarem uma estratégia governista, de alinhamento ao governo federal. 
Mais importante e antes dos eleitores, contariam as disposições e alianças das lideranças partidárias municipais.

A identificação da influência exercida pelo controle sobre o governo federal em relação aos resultados no plano municipal não deve conduzir-nos à suposição simplificadora de que este constitua um espelho das tendências nacionais. Um exame dos resultados eleitorais registrados nas eleições municipais, cotejados à identificação da família ideológica que controlava previamente cada prefeitura (Tabela 6), permite-nos perceber o fator de path-dependency que interage e modela o impacto das tendências nacionais sobre a competição local. Os vitoriosos em 2008 localizam-se, predominantemente, dentro do mesmo campo ideológico dos ocupantes prévios dos respectivos governos municipais, com deslocamentos interblocos ideológicos ocorrendo de modo menos frequente. 0 que parece mudar, nesta perspectiva, não são os partidos ou as famílias ideológicas nos municípios, mas o alinhamento dos partidos em relação ao governo federal.

Tabela 6

Relação entre partido vencedor (2008) e bloco ideológico do partido do governo anterior

\begin{tabular}{|c|c|c|c|}
\hline prévio & Direita & Centro & Esquerda \\
\hline vencedor & 63,0 & 25,1 & 11,9 \\
\hline DEM & 59,7 & 23,7 & 16,6 \\
\hline PP & 29,9 & 55,8 & 14,3 \\
\hline PSDB & 36,1 & 49,3 & 14,6 \\
\hline PMDB & 34,4 & 21,0 & 44,6 \\
\hline PDT & 33,6 & 24,9 & 41,5 \\
\hline PSB & 27,9 & 24,1 & 48,0 \\
\hline PT & & & \\
\hline
\end{tabular}

Fonte: Tribunal Superior Eleitoral (TSE).

Se esta interpretação estiver correta, estar no governo federal constitui um recurso importante para conquistar ou manter governos municipais. Uma perspectiva menos estática para analisar este fenômeno consiste em incorporar informação referente ao fluxo SAÍDA-ENTRADA, produzido pela competição eleitoral nos municípios. Ou seja, qual partido perde, qual ganha, ou se ocorre uma recondução da mesma legenda. Como se está procurando verificar o impacto do alinhamento ao governo federal sobre os resultados locais, este fluxo foi ordenado segundo as categorias "governo" e "oposição", sempre em relação à esfera federal. A frequência verificada para os diferentes fluxos eleitorais pode ser examinada através dos dados fornecidos pela Figura 1: 
Figura 1

Fluxo eleitoral, em relação governo federal (\%)

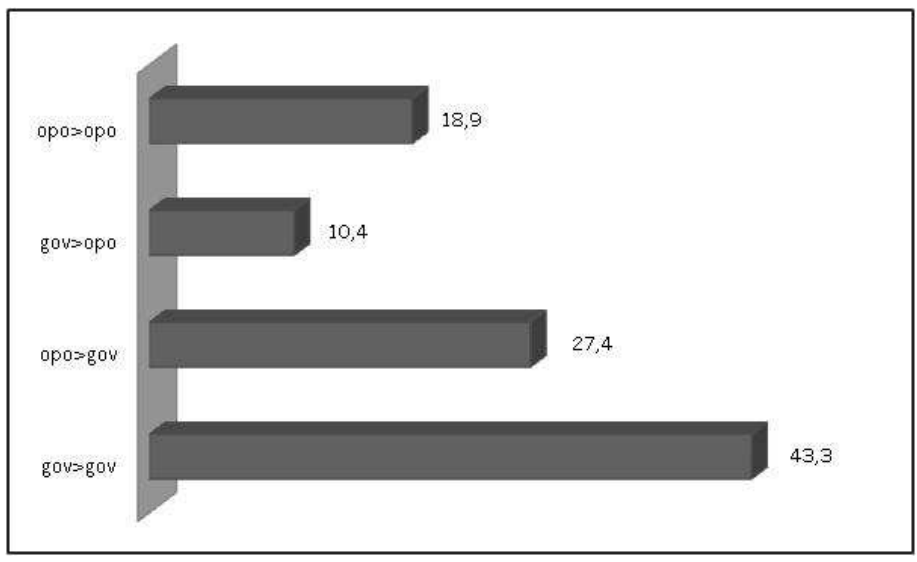

A ocorrência mais frequente $(43,3 \%)$ é aquela em que os resultados eleitorais não alteram o controle da prefeitura por partido alinhado ao governo federal. Não quer dizer que seja a mesma legenda partidária, mas a circulação ou alternância do governo municipal verifica-se entre partidos aliados no plano nacional. Significativa também é a proporção de casos $(27,4 \%)$ em que partidos oposicionistas são deslocados do governo municipal por legendas governistas. No total, as eleições municipais de 2008 levaram partidos alinhados ao governo federal à vitória em 70,7\% dos mais de 5,5 mil municípios brasileiros. Situação distinta é aquela observada em redutos oposicionistas, onde partidos de oposição federal logram manter o controle sobre o governo municipal, fenômeno verificado em 18,9\% dos municípios. Contudo, o caso mais raro, observado em cerca de apenas 1 de cada 10 municípios brasileiros, consiste na conquista, por partidos oposicionistas, de municípios antes controlados por legendas governistas.

Desagregando esta informação segundo sua frequência nos diferentes estados brasileiros, observa-se que redutos governistas (gov>gov) são mais verificados em um conjunto heterogêneo de estados, como Acre, Alagoas, Amapá, Mato Grosso do Sul, Paraná, Rio de Janeiro, Rio Grande do Norte, Rio Grande do Sul e Santa Catarina. Municípios oposicionistas conquistados por legendas governistas aparecem com mais frequência no Amazonas, Bahia, Ceará, Mato Grosso, Pará, Pernambuco, Piauí e Sergipe, que possuem em comum o alinhamento de seus governadores estaduais ao governo federal após 2006. Os redutos oposicionistas (opo>opo) concentram-se em Minas Gerais, São Paulo e Paraíba, todos estados dirigidos por governadores de oposição ao governo federal. Finalmente, as conquistas oposicionistas (gov>opo) aparecem principalmente nos pequenos estados de Rondônia e Roraima.

Esta última informação introduz à análise um dado novo: a presença e eventual influência dos governadores estaduais. Conforme Abrucio (1988), em função de recursos políticos e administrativos disponíveis e maior proximidade aos municípios e às bases eleitorais de deputados estaduais e federais, governadores disporiam de forte influência sobre os resultados da competição estadual e municipal, 
atuando ainda como veto-players na arena federal. Se esta hipótese for consistente, deve-se considerar a medida em que os resultados governistas federais nos municípios possam ser afetados (reforçados ou mitigados) pela influência dos governadores estaduais. Em outras palavras, faz diferença para a força local de partidos governistas se estes contam com um governador alinhado ou contrário a esta posição?

Pode-se responder a esta questão considerando o grau de alinhamento entre governos MUNICIPAL, ESTADUAL E FEDERAL. É da natureza de instituições federativas a configuração de governos divididos (FIORINA, 1996), nos quais a oposição nacional controla administrações subnacionais, na esfera estadual ou municipal. Desta forma, encontramos quatro diferentes combinações governo/oposição, quando consideramos cada município, seu respectivo estado e, evidentemente, o governo federal: GOV +GOV + GOV, quando município e estado estão sob controle de partido vinculado à coalizão governante nacional; em GOV +OPO + GOV, o partido governante no município é alinhado com o governo federal, mas o governo estadual está com a oposição nacional; OPO + GOV + GOV, equivale à situação inversa, município oposicionista e governo estadual governista em relação ao Executivo Federal; finalmente $\mathrm{OPO}+\mathrm{OPO}+\mathrm{GOV}$ representa situação em que tanto o município como a administração estadual estão alinhados com a oposição federal. Neste ponto, a interrogação consiste em saber como estas diferentes configurações influenciam a competição eleitoral nos municípios. O resultado da competição é levado em conta em termos de GOVERNO (vence partido alinhado ao governo federal) ou OPOSIÇÃO (vence legenda integrante da oposição federal). Os achados são apresentados na Figura 2, na qual a área escura da barra representa o percentual de vitórias do GOVERNO e a área clara, vitórias da OPOSIÇÃO, segundo as quatro combinações apontadas:

Figura 2

Alinhamento intergovernamental e resultado eleitoral

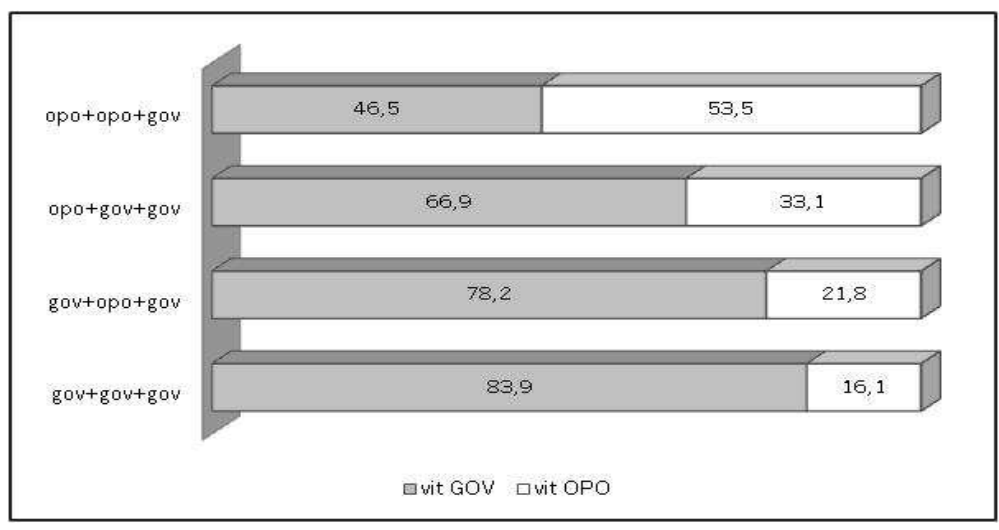

Quando as três esferas de governo estão alinhadas, a probabilidade de vitória de partido da coalizão governista nacional é muito elevada: mais de $80 \%$ dos municípios sob esta configuração apresentam resultado de vitória governista. Não dispondo de acesso a recursos (spoil system, pork) municipais, estaduais ou federais, oposições locais não parecem ser suficientemente competitivas. E o 
MARENCO DOS SANTOS, A. Topografia do Brasil profundo: votos, cargos e...

que acontece quando entre partido governista na administração municipal e o governo federal interpõese um governador oposicionista? Isto aumenta significativamente as chances de partido não-governista conquistar o governo municipal, contando com eventual apoio da administração estadual? A julgar pela frequência de vitórias oposicionistas sob esta configuração, a resposta deve ser negativa. $O$ incremento em prefeituras conquistadas por partidos oposicionistas em estados governados pela oposição nacional é inferior a 6 pontos percentuais. Mais de 4 em cada 5 cidades nesta situação (gov+opo+gov) reelegem partidos alinhados ao governo federal. A interpretação oferecida por estes dados deve servir para relativizar a influência efetiva dos governadores sobre a competição local. Se, quando governadores estão alinhados ao governo federal, torna-se complexo isolar e controlar a influência de cada um sobre os resultados, circunstâncias de desalinhamento entre governo estadual, de um lado, e governos municipal e federal, de outro, permitem que se controle de modo mais seguro a influência efetiva dos governadores.

Invertendo os lados e considerando municípios controlados por partidos oposicionistas em estados administrados por partidos alinhados ao governo federal, percebe-se um impacto maior nas vitórias da oposição. Os 33,1\% de municípios onde a oposição federal logra manter-se à frente da administração municipal, desafiando os governos estadual e federal, talvez constituam o que de mais próximo seja possível encontrar correspondente ao padrão de mandonismo local, identificado na literatura de estudos sobre municípios no Brasil, ou seja, a presença de um controle autárquico do poder local, fundado em bases tradicionais e de lealdades pessoais. Estes são também municípios em que os percentuais de população urbana $(48,2 \%)$ e renda per capita média ( $R \$ 95)$ estão entre os mais baixos no país ${ }^{3}$, reforçando a hipótese de que sua feição politicamente autárquica em relação a alinhamentos estaduais e federais seja potencializada por uma demografia mais tradicional. De qualquer forma, nada menos do que 2/3 destes municípios apresentam vitória de partidos alinhados ao governador e ao Presidente da República, indicando o declínio do mandonismo local.

Finalmente, vitórias oposicionistas adquirem proporção ligeiramente predominante apenas quando governo municipal não alinhado ao governo federal, encontra apoio no governador de seu estado, igualmente oposicionista em relação ao Presidente da República. A sinergia município/estado parece potencializar a competitividade dos partidos oposicionistas na esfera local, que alcançam vitória em $53,5 \%$ dos casos sob esta configuração. Aqui também podemos encontrar os níveis mais elevados de renda per capita e taxas de urbanização.

\section{Conclusão}

Este artigo analisou os padrões de competição eleitoral nos 5,5 mil municípios brasileiros. Os resultados mostraram que graus de competitividade - medidos pela frequência de vitoriosos com menos de $50 \%$ dos votos - crescem conforme o tamanho do município, ao mesmo tempo que dominância é mais frequente em micro e pequenas cidades. A conquista de administrações municipais revela não haver uma correspondência entre famílias ideológicas e grau de urbanização, refutando tese consagrada

\footnotetext{
${ }^{3}$ IBGE (2009).
} 
pela qual partidos conservadores deveriam dominar municípios rurais, enquanto partidos de centro e esquerda prevaleceriam em centros mais urbanos. A comparação da série de eleições municipais realizadas em 2000, 2004 e 2008 mostra uma tendência de crescimento de partidos de esquerda e legendas que integram a coalizão governista federal, com acentuado declínio de partidos de oposição ao governo federal. A hipótese de que alinhamento ao governo federal possa constituir importante capital político na competição eleitoral local foi confirmada, ainda, quando observou-se que a razão de probabilidade de conservação do governo municipal por um mesmo partido na eleição seguinte está associada à sua participação na coalizão de governo federal. Da mesma forma, esta continuidade apresenta probabilidade negativa quando relacionada à região nordeste, contrariando o bom senso convencional que supõe uma relação entre sua demografia rural e eleitorado com menor renda, com maiores chances para domínio tradicional. Níveis de gasto público pareceram não afetar chances de manutenção do posto. Por outro lado, o incremento de competição eleitoral não implica em deslocamentos interblocos ideológicos: a maioria das mudanças partidárias nas administrações municipais ocorre dentro da mesma família ideológica. Alinhamento com o governo federal constitui o grande trunfo para candidatos locais: eleições em que partidos que integram o governo federal foram vitoriosos correspondem a 70,1\% dos municípios no pleito municipal de 2008. Em contraste, partidos oposicionistas conseguiram conquistar prefeituras dominadas por governistas em não mais do que 1 de cada 10 municípios brasileiros. A principal conclusão indica a presença prevalente de um componente nacional na disputa local, somente neutralizado de modo parcial quando prefeitura e governo estadual estão nas mãos de partidos oposicionistas.

\section{Referências Bibliográficas}

Abranches, S. "Presidencialismo de Coalizão: O Dilema Institucional Brasileiro". Dados, Rio de Janeiro, vol.31, n 1, p.5.34, 1988.

Abrucıo, F. Os Barões da Federação: Os Governadores e a Redemocratização Brasileira. São Paulo: Hucitec, 1988.

AlmeidA, A. C. A Cabeça do Eleitor. Estratégia de Campanha, Pesquisa e Vitória Eleitoral. São Paulo: Record, 2008.

Almeida, M. H. e Carneiro, P. "Liderança Local, Democracia e Políticas Públicas no Brasil”. Opinião Pública, Campinas, vol. IX, n' 1, p. 124-147, 2003.

AmES, B. Os Entraves da Democracia no Brasil. Rio de Janeiro: Editora FGV, 2003.

Amorim Neto, O. "Gabinetes Presidenciais, Ciclos Eleitorais e Disciplina Legislativa no Brasil". Dados, Rio de Janeiro, vol. $43, n^{\circ} 3$, p. $479.517,2000$.

. O Brasil, Lijphart e o Modelo Consensual de Democracia. In: INACIO, M. e RENNÓ, L. (orgs.). Legis/ativo Brasileiro em Perspectiva Comparada. Belo Horizonte: Ed. UFMG, 2009.

AnASTASiA, F.; CASTRO, M. e Nunes, F. Desde Entonces Hasta Ahora: las Condiciones y las Instituciones de La Democracia Después de 1988. In: Alcantara, M. e Ranulfo, C. (orgs.). La Democracia Brasileña: Balance y Perspectivas Para El Siglo XXI. Salamanca: Ediciones Universidad Salamanca, 2008.

Avelar, L. e Walter, M. I. "Lentas Mudanças: O Voto e a Política Tradicional”. Opinião Pública, Campinas, vol. 14, n 1, p. $96 \cdot 122,2008$. 


\section{MARENCO DOS SANTOS, A. Topografia do Brasil profundo: votos, cargos e...}

BoIssevain, J. "Patronage in Sicily". Man, Londres, vol. 1, n 1, p. 18.33, 1966.

Braga, M. S. O Processo Partidário-Eleitoral Brasileiro: Padrões de Competição Política (1982-2002). São Paulo: Humanitas / Fapesp, 2006.

Campello de Souza, M. C. Estado e Partidos Políticos no Brasil (1930 a 1964). São Paulo: Alfa-Ômega, 1976.

"Federalismo no Brasil: Aspectos Politico-Institucionais". Revista Brasileira de Ciências Sociais, São Paulo, vol. $21, n^{\circ} 6$, p. $7.40,2006$.

Carderello, A. La reeleccion inmediata del ejecutivo a nivel sub. nacional. Un estudio de tres casos. Porto Alegre: UFRGS, 2009.

Carvalho, J. M. "Barbacena: A Família, a Política e uma Hipótese". Revista Brasileira de Estudos Políticos, Rio de Janeiro, vol. 20, p. 153-194, 1966.

\section{7.}

. "Mandonismo, coronelismo, clientelismo: uma discussão conceitual". Dados, Rio de Janeiro, vol. 40, n²,

Carvalho, N. E no Início Eram as Bases: Geografia Política do Voto e Comportamento Legislativo no Brasil. Rio de Janeiro: Revan, 2003.

Cox, G. Making Votes Count. Strategic Coordination in the World's Electoral Systems. Cambridge: Cambridge University Press, 1997.

DAHL, R. Polyarchy. Participation and Opposition. New Haven: Yale University Press, 1971.

DEUTSCH, K. Os nervos do governo: análise dos modelos de comunicação e do controle político. Rio de Janeiro: Bloch, 1970.

DuVerger, M. Les Partis Politiques. Paris: Armand Colin, 1951.

EISENSTADT, S. Modernization: Protest and Change. New Jersey: Prentice-Hall, 1966.

Figuelredo, A. e Limongl, F. Executivo e Legislativo na Nova Ordem Constitucional. Rio de Janeiro: Editora FGV, 1999.

FIORINA, M. Divided Government. New York: Longman Classics, 1996.

GraziAno, L. Patron - client relationship in Southern Italy. In: Schmitd, S.W. et al (eds.). Friends, followers, and factions. Berkeley: University of California Press, 1977.

Hagopian, F. The Politics of Oligarchy. The Persistence of Traditional elites in Contemporary Brazil. Boston: Massachusetts Institute of Technology, 1986.

IBGE. Sinopse preliminar do censo demográfico, vol. 7. Rio de Janeiro: IBGE, 2000.

Contas Regionais do Brasil, 2003-2007. Brasília: IBGE, 2009.

InÁcIO, M.; Rennó, L. (orgs.). Legislativo Brasileiro em Perspectiva Comparada. Belo Horizonte: Editora UFMG, 2009.

JaguariBe, H. Desenvolvimento Econômico e Desenvolvimento Político. Rio de Janeiro: Editora Fundo de Cultura, 1962.

Kerbauy, M. T. "As Câmaras Municipais Brasileiras: Perfil de Carreira e Percepção Sobre o Processo Decisório Local". Opinião Pública, Campinas, vol. XI, n² 2, p. 337-365, 2005.

LANDÉ, C. The Dyadic Basis of Clientelism", In: SCHMIDT, S. et al. Friends, Followers and Factions: A Reader in Political Clientelism. Berkeley: University of California Press, 1977.

Lavareda, A. Emoções Ocultas e Estratégias Eleitorais. Rio de Janeiro: Objetiva, 2009.

LEAL, V. N. Coronelismo, enxada e voto. São Paulo: Alfa-Ômega, 1975. Press, 1977.

Coronelismo: the Municipality and Representative Government in Brazil. Cambridge: Cambridge University

LIPSET, S. Political Man: The Social Bases of Politics. Baltimore: The Johns Hopkins University Press, 1959. 
LOPEZ, F. "A Política Cotidiana dos Vereadores e as Relações Entre Executivo e Legislativo em Âmbito Municipal: O Caso do Município de Araruama". Revista de Sociologia e Política, Curitiba, vol. 22, p. 153-177, 2004.

Nicolau, J. e PoWer, T. Instituiçóes Representativas no Brasil: Balanço e Reforma. Belo Horizonte: Editora UFMG, 2007.

Palermo, V. "Como se Governa o Brasil? O Debate sobre Instituições Políticas e Gestão de Governo". Dados, Rio de Janeiro, vol. 43, n 3, p. 521.557, 2000.

PANG, E. Coronelismo e Oligarquias, 1889-1943. Rio de Janeiro: Civilização Brasileira, 1979.

Pereira, C.; Power, T.; Rennó, L. "Agenda Power, Executive Decree Authority, and the Mixed Results of Reform in the Brazilian Congress". Legislative Studies Quarterly, lowa, XXXIII, 5·34, 2008.

Piquet, L.; Almeida, M. H. "Definindo a Arena Política Local: Sistemas Partidários Municipais na Federação Brasileira". Dados, Rio de Janeiro, vol. 51, n² 2, p. 403.442, 2008.

PNUD. Atlas do Desenvolvimento Humano no Brasil. PNUD, 2003.

QueIroz, M. I. O Mandonismo Local na Vida Política Brasileira e Outros Ensaios. São Paulo: Alfa-Ômega, 1976.

Rodrigues, L. Partidos, Ideologia e Composição Social. Um Estudo das Bancadas Partidárias na Câmara dos Deputados. São Paulo: Edusp, 2002.

Mudanças na Classe Política Brasileira. São Paulo: Publifolha, 2006.

SADEK, M. T. "Judiciário: mudanças nem sempre à vista". Cadernos ADENAUER, Rio de Janeiro, vol. VII, p. 139-156, 2006.

Santos, F. O Poder Legislativo no Presidencialismo de Coalizão. Belo Horizonte: Editora UFMG, 2003.

SHILS, E. Center and Periphery. Chicago: University of Chicago, 1974.

SOARES, G. D. Sociedade e política no Brasil: desenvolvimento, classe e política durante a segunda República. São Paulo: Difusão Europeia do Livro, 1973.

ScotT, J. Patron-client Politics and Political Change in Southeast Asia. In: SCHMIDT, S. et al. (orgs.). Friends, Followers, and Factions. Berkeley: University of California Press, 1977.

SouzA, C. "Federalismo e Conflitos Distributivos: Disputa dos Estados por Recursos Orçamentários Federais". Dados, Rio de Janeiro, vol. 46, n² 2, p. 345-384, 2003.

Tomı, F. "The creation of municipalities after the 1988 constitution". Revista Brasileira de Ciências Sociais, São Paulo, vol. 1, special Ed. 2005.

Vanhanen, T. "A New Dataset For Measuring Democracy, 1810-1998”. Journal of Peace Research, Oslo, vol. 37, n², p. $251 \cdot 265,2000$.

Vianna, L. W.; Melo, M.; Carvalho, M. A. e Burgos, M. Corpo e Alma da Magistratura Brasileira. Rio de Janeiro: Editora Revan, 1997.

André Marenco dos Santos · amarenco@terra.com.br

Submetido à publicação em junho de 2011. Aprovado para publicação em agosto de 2011. 